\title{
Systematic review of resource utilization in the hospital management of deliberate self-harm
}

\author{
JULIA M. A. SINCLAIR ${ }^{1 *}$, ALASTAIR GRAY ${ }^{2}$ AND KEITH HAWTON ${ }^{1}$ \\ ${ }^{1}$ Centre for Suicide Research, Warneford Hospital, University of Oxford, UK; ${ }^{2}$ Health Economics \\ Research Centre, Department of Public Health, University of Oxford, UK
}

\begin{abstract}
Background. Deliberate self-harm (DSH) is a significant public health problem, representing a major burden in terms of morbidity to the individual and health-service utilization. While clinical guidelines suggest good practice for the short-term hospital management of DSH, there remains considerable variability in the way that services are provided.
\end{abstract}

Method. A systematic review of the literature was undertaken to examine the current evidence on hospital resource use and costs involved in the short-term hospital management of adults following DSH and to elucidate the factors that influence these differences, in terms of clinical characteristics and service provision.

Results. Twenty-one papers reporting on 17 studies met the inclusion criteria for review. Clinical characteristics associated with an increase in resource use included overdose with tricyclic antidepressants (TCAs) compared with selective serotonin re-uptake inhibitors (SSRIs) (weighted ratio $2 \cdot 6: 1$ ) and co-ingestion of alcohol with SSRIs. Variations in service provision, including medical admissions policy and provision of a specialist liaison service, affected resource utilization independently of the clinical needs of patients.

Conclusions. Overdoses of TCAs incur substantially greater hospital costs than overdoses of SSRIs. Variations in the medical seriousness of DSH, and in the structure of service provision, affect the resources used in its short-term hospital management, with little evidence about the impact these differences have on clinical outcome. Research is needed to evaluate the impact of different styles of service provision on outcome, and to incorporate these factors into the trial design of future cost-effectiveness studies of interventions following DSH.

\section{INTRODUCTION}

Deliberate self-harm (DSH) is a significant public health problem. One estimate is that approximately 170000 people a year present to hospital in the UK following an episode (Kapur et al. 1999b). From a societal perspective, this represents a major burden in terms of morbidity to the individual, health-service utilization and

\footnotetext{
* Address for correspondence: Dr Julia M. A. Sinclair, Department of Psychiatry, Warneford Hospital, Oxford OX3 7JX, UK.

(Email: julia.sinclair@psych.ox.ac.uk)
}

life years lost. Although clinical guidelines have been produced suggesting good practice for the short-term management of DSH (Royal College of Psychiatrists, 1994, 2004; NICE, 2004), there remains considerable variability in the way that services are provided within and between different health systems (Hultén et al. 2000; Kapur et al. 2002a; Bennewith et al. 2004), and there is no evidence as to which service model is most effective.

There has been much clinical and epidemiological research into the risk factors associated 
with DSH in different countries (Platt et al. 1992; Schmidtke et al. 1996). Less research has focused on either the economic aspects or the resource burden associated with DSH (Byford et al. 2001, 2003). As DSH is a behaviour associated with most mental illnesses, it is difficult to determine resource use directly attributable to it, rather than that due to an underlying psychiatric condition, or other cause. Determining these costs has implications for evaluating the cost-effectiveness of interventions aimed at the secondary prevention of DSH.

In the UK the majority of DSH patients who present to health services attend the emergency department of their local hospital, while $15 \%$ of medically less serious DSH episodes are managed in primary care alone (Jick et al. 2004). Although there are major differences in the structure of health provision between countries, the role of the emergency department is a reasonably constant component, making international comparisons of the immediate hospital management more valid than across more disparate service structures (e.g. primary care). In addition, the resources involved in this immediate management can be attributed more directly to $\mathrm{DSH}$, rather than to any underlying cause.

This study was designed to estimate hospital resource use of patients following DSH. The specific aims were:

(1) to review the current evidence on hospital resource use and costs involved in the short-term management of adults following DSH;

(2) to examine the factors that influence differences in hospital resource use, in terms of clinical characteristics (demand factors) and service provision (supply factors).

\section{METHOD}

A systematic review of the literature on hospital resource use by DSH patients was undertaken. Studies were included if they fulfilled the following criteria:

(1) Reported primary data in adult populations $(90 \%>16$ years). Economic modelling and population-based studies not reporting primary data were excluded.
(2) Reported detailed hospital resource use in the short-term management of patients presenting following an episode of DSH.

Cost-effectiveness analyses were included if they met these criteria. Where a study was reported in more than one article, data were abstracted from each of the papers if they were examining different aspects of resource use, otherwise from the most recent report. Bibliographies of eligible papers were checked for possible relevant studies. Where there were uncertainties about the data, authors were approached for clarification. Because of the paucity of evidence, there were no quality exclusion criteria, although quality was assessed. Studies examining resource use before or after an episode of DSH but not involving the immediate management of the index episode (see criterion 2 above) fell outside the remit of this review.

\section{Search strategy}

Electronic searches of Medline (1966-2004), EMBASE (1980-2004), PsycINFO (1872-2004) and Biological Abstracts (1985-2004), Web of Science (1981-2004) and CINAHL (1982-2004) were carried out using subject headings and free text terms: 'attempted suicide', 'self-injurious behaviour', 'overdose', 'deliberate self-harm', 'suicidal behaviour', 'parasuicide', 'drug overdose', combined with terms for 'costs', 'cost analysis', 'evaluation', 'cost-effectiveness', 'service utilization', 'resource use'.

Included papers were checked for additional references not found electronically. We reviewed screened papers independently and any disagreements on inclusion discussed and resolved (see Fig. 1).

\section{Data abstraction}

Data were abstracted from each paper using a structured pro forma, and summarized in table form. A simple 10-point check-list was developed to score studies on the key elements for a simple economic evaluation (Drummond et al. 1997). This allowed the design of studies to be scored out of a maximum of 15 points (Table 1 ).

\section{RESULTS}

Twenty-one papers reporting on 17 studies met the inclusion criteria for the review (Table 2). 


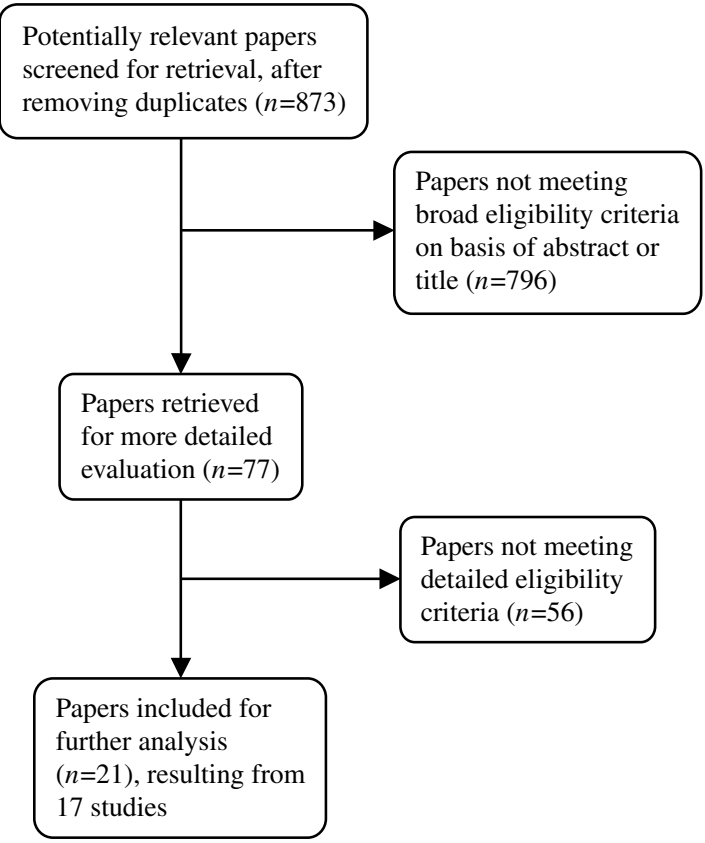

FIG. 1. Summary of results of search for relevant papers on resource use following deliberate self-harm (DSH).

Nine papers (D'Mello et al. 1995; Revicki et al. 1997; Stoner et al. 1997; Palmer et al. 1998; Kapur et al. 1999 a, 2001; Bosch et al. 2000; Ramchandani et al. 2000; Whyte et al. 2003) compared resource use in the hospital management of a single episode of deliberate self-poisoning (DSP) with different classes of antidepressant drugs, primarily selective serotonin re-uptake inhibitors (SSRIs) and tricyclic antidepressants (TCAs) (see Table 2).

Eight papers (Robicsek et al. 1993; Yeo, 1993; Runeson \& Wasserman, 1994; Waller et al. 1994; Gunnell et al. 1996; Whyte et al. 1997; Kapur et al. 1999b, 2002b) reported studies of consecutive DSH presentations at one or more hospital sites, including the cost per episode of DSH, differences in resource use between centres, or the resource use of DSH patients compared with that of patients presenting with other forms of injury (see Table 2).

Two papers reported studies that examined the effect of variation in hospital service provision on resource use. One study from the USA in 1974 evaluated the effect of managing patients on a new respiratory care unit compared with its historical control (Piper \& Griner, 1974). A recent UK paper (Kapur et al. 2003) presented a secondary analysis of data from an earlier UK study (Kapur et al. 2002b) to examine what impact the structure of hospital services had on resource use in the management of DSH (see Table 2).

Finally, two studies stand alone (Table 3). One from the USA examined the different patient characteristics and relative resource use of patients presenting with accidental paracetamol poisoning compared with paracetamol used in DSH (Schiodt et al. 1997). The second calculated resource utilization of DSH patients admitted to an intensive therapy unit (ITU) in Sri Lanka over a 5-year period (Gunawardana \& Abeywarna, 1997).

Given the variability of resources used and how these were costed and recorded between studies (see Table 2), as well as the differences in health-care systems and the time over which the studies were conducted, it would be meaningless to combine the results in a traditional form of meta-analysis. Results are therefore presented below in a descriptive synthesis, the studies grouped in the following categories: first the studies reporting on overdoses with antidepressant medication; then those studies that calculated resource use for samples of consecutive DSH populations; the impact of epidemiological differences in methods of DSH; the effect of different service structures and unit costs; and finally those studies that compare DSH patient resource use with other forms of injury and poisoning.

\section{Studies examining resource use following overdose with antidepressant medication}

It was possible to aggregate the findings from seven of the nine papers examining resource use resulting from antidepressant overdose (D'Mello et al. 1995; Revicki et al. 1997; Stoner et al. 1997; Palmer et al. 1998; Kapur et al. 1999 a, 2001; Ramchandani et al. 2000). This showed that the unweighted average cost of TCA overdose was 2.7 times (range 2.01-4.26) that of managing an overdose of an SSRI. Adjusting the ratio of average TCA : SSRI costs for relative sample size gave a weighted average ratio of $2 \cdot 6: 1$.

The management of venlafaxine overdose was studied separately in one study (Whyte et al. 2003). This found that because of its proconvulsive potential in overdose (Sinclair et al. 
Table 1. Criteria used to rate studies

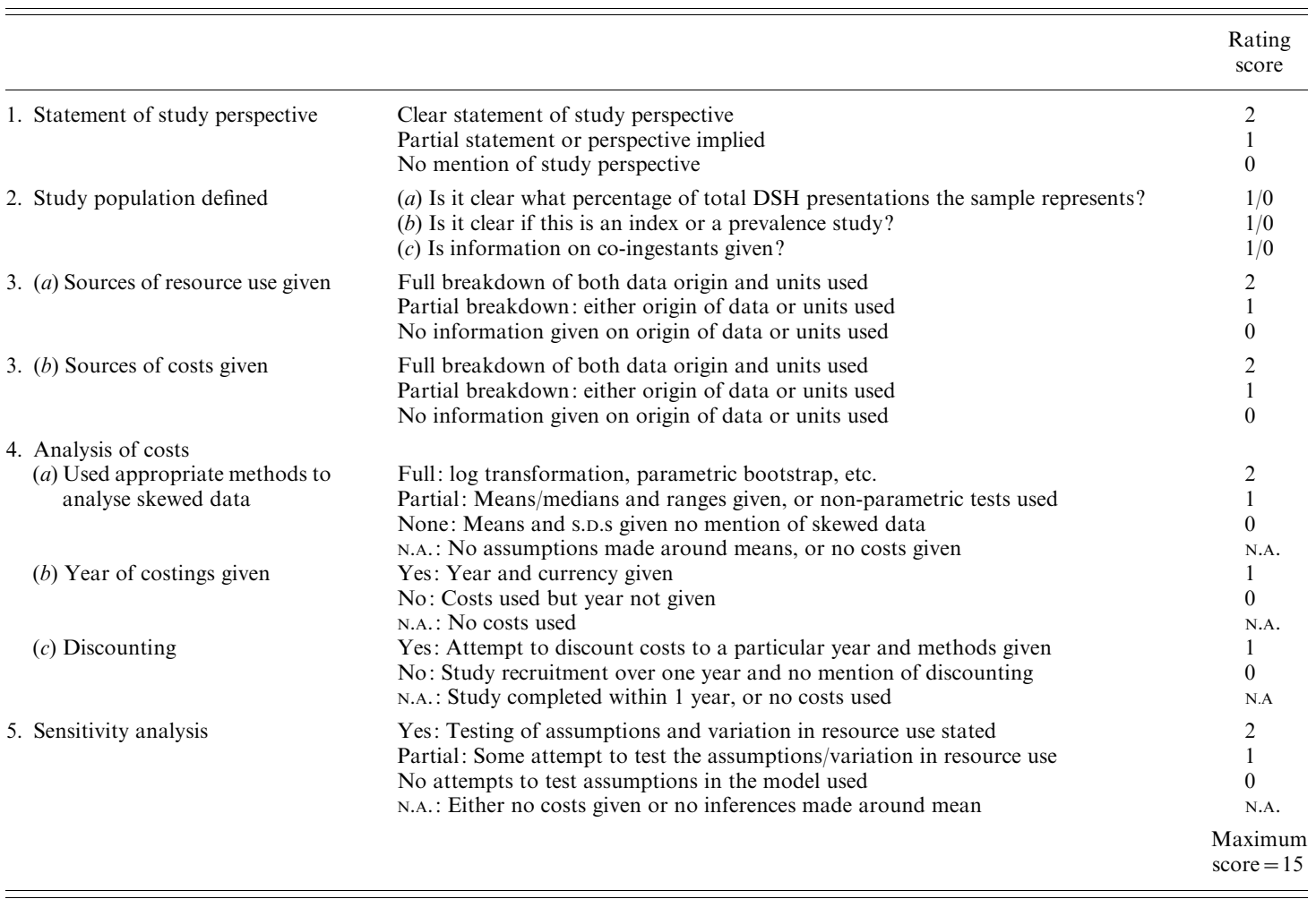

DSH, Deliberate self-harm.

1998), management of complications required more time in ITU and hospital than for overdoses with SSRIs. This study excluded overdose with dothiepin from the reference TCA group, which, because of its significant depression of respiratory function in overdose (Buckley et al. 1994), is likely to lessen the difference between the groups.

\section{Effect of co-ingestants on resource utilization}

One major factor affecting the relative difference in resources required to manage DSP with any class of antidepressant medication is whether the effect of co-ingestants was considered. Four reports gave specific information on the percentage of patients who consumed pro-convulsive or respiratory depressant drugs or alcohol, in addition to the primary antidepressant compound (Stoner et al. 1997; Palmer et al. 1998; Bosch et al. 2000; Whyte et al. 2003). However, the studies by Bosch et al. (2000) and Whyte et al. (2003) gave insufficient detail as to the effect of these additional compounds on resource use. The other two studies specifically compared the effect on resource use of co-ingestion of alcohol with antidepressant overdose (Stoner et al. 1997; Palmer et al. 1998). In the study by Stoner et al. (1997), 43/171 $(25 \%)$ of the TCA group and $16 / 49(33 \%)$ of the SSRI group also ingested alcohol $(z=1 \cdot 115$, $p=0 \cdot 26$ ). This increased the mean resource use compared to antidepressant alone by $10.4 \%$ in the TCA group (from $\$ 606$ to $\$ 670$ ) and $61 \%$ (from \$252 to \$407) in the SSRI group. In the other study (Palmer et al. 1998), 60/542 (11\%) of the TCA group and 15/80 (19\%) of the fluoxetine group $(z=1 \cdot 05, p=0 \cdot 30)$ also ingested alcohol, decreasing the mean resource use by $39 \%$ in the TCA group (from \$5764 to \$1269) but increasing it by $55 \%$ in the fluoxetine group (from \$1269 to \$1973) when compared to antidepressant alone. No explanation is given for why co-ingestion of alcohol with TCAs reduces the resources required for management; the 
Table 2. Summary of antidepressant overdose studies

\begin{tabular}{|c|c|c|c|c|}
\hline $\begin{array}{l}\text { Authors } \\
\text { (date, place) }\end{array}$ & $\begin{array}{c}\text { Quality } \\
\text { rating (\%) }\end{array}$ & Study details & $\begin{array}{l}\text { Episode (patient) } \\
\text { number }\end{array}$ & Summary of resource use \\
\hline $\begin{array}{l}\text { D'Mello et al. } \\
\text { (1995, USA) }\end{array}$ & 20 & $\begin{array}{l}\text { Retrospective audit of } 200 \text { consecutive DSH presentations following drug overdose } \\
\text { between } 1 / 1 / 1991 \text { and } 31 / 12 / 1993 \text {. Inclusion criteria; intentional OD using antidepressant; } \\
\text { available cost data. } 12 \% \text { of sample included. M : F } 1: 2 \cdot 5\end{array}$ & $\begin{array}{l}23 \text { patients } \\
\text { TCA }=14 \\
\text { SSRI }=6 \\
(+3 \text { Trazodone) }\end{array}$ & $\begin{array}{l}\text { Hospital costs, mean (s.D.) } \\
\text { TCA } \$ 22923(27629) \\
\text { SSRI } \$ 5379(2362) \\
\text { TCA }: \text { SSRI costs }=\mathbf{4} \cdot \mathbf{2 6}: \mathbf{1}\end{array}$ \\
\hline $\begin{array}{l}\text { Stoner et al. } \\
\text { (1997, USA) }\end{array}$ & 40 & $\begin{array}{l}\text { Retrospective audit of all patients admitted following DSP, with antidepressants listed as } \\
\text { one of three main substances used, between } 1 / 8 / 1987 \text { and } 31 / 12 / 1995 . \mathrm{M}: \mathrm{F} 1: 1 \cdot 3 \text {. } \\
\text { Differential resource use with co-ingestants given (see text) }\end{array}$ & $\begin{array}{l}262 \text { patients } \\
\text { TCA }=171 \\
\text { HA }=40 \\
\text { SSRI }=49 \\
(+2 \text { MAOI) }\end{array}$ & $\begin{array}{l}\text { Hospital costs, mean } \\
\text { TCA (based on } 68 \% \text { of cases) } \$ 635 \\
\text { HA (based on } 75 \% \text { of cases) } \$ 451 \\
\text { SSRI (based on } 90 \% \text { of cases) } \$ 252 \\
\text { TCA : SSRI costs }=\mathbf{2 \cdot 5 : 1}\end{array}$ \\
\hline $\begin{array}{l}\text { Revicki et al. } \\
\text { (1997, USA) }\end{array}$ & 80 & $\begin{array}{l}\text { Prospective, multi-centre study of DSP with single antidepressant (TCA or fluoxetine) } \\
\text { between } 10 / 1990 \text { and } 03 / 1993 \text {. Inclusion criteria; ingestion of single antidepressant drug, } \\
\text { laboratory confirmation of OD, retrievable hospital bills. M : F } 1: 1 \cdot 16 \text {. Of } 622 \text { eligible } \\
\text { patients }(\text { TCA }=542 \text {, fluoxetine }=80), 136(21 \%) \text { fulfilled inclusion criteria }\end{array}$ & 136 patients & $\begin{array}{l}\text { Hospital costs, mean (s.D.) } \\
\text { TCA }(n=121) \$ 5764(821) \\
\text { Fluoxetine }(n=15) \$ 1269(382) \\
\text { TCA }: \text { SSRI costs }=\mathbf{2} \cdot \mathbf{1 5}: \mathbf{1}\end{array}$ \\
\hline $\begin{array}{l}\text { Palmer et al. } \\
\text { (1998, USA) }\end{array}$ & 80 & $\begin{array}{l}\text { Paper based on Revicki et al. (1997) study above. Reports an additional } 75 \text { patients ( } 15 \\
\text { fluoxetine + alcohol OD, } 60 \mathrm{TCA}+\text { alcohol OD). Laboratory confirmation of OD, costs } \\
\text { taken from billing data }\end{array}$ & 75 patients & $\begin{array}{l}\text { Hospital costs, mean (s.D.) } \\
\text { TCA + alcohol } \$ 3529(423) \\
\text { Fluoxetine + alcohol } \$ 1973(588) \\
\text { TCA : SSRI costs }=\mathbf{1} \cdot \mathbf{7 9}: \mathbf{1}\end{array}$ \\
\hline $\begin{array}{l}\text { Kapur et al. } \\
(1999 a, \text { UK) }\end{array}$ & 71 & $\begin{array}{l}\text { Retrospective audit of all DSP presentations ( }>16 \text { years) due to TCA or SSRI OD to four } \\
\text { teaching hospitals over a } 4 / 52 \text { period in } 11 / 1994 \text {. Subgroup }(12 \%) \text { of patients reported in } \\
\text { Kapur et al. }(1999 \mathrm{~b}) \text {. M : F } 1: 1 \cdot 04 \text {. Past DSH in } 37 \% \text {. Costs divided into ED assessment, } \\
\text { IP days, ITU days, psychiatric assessment }\end{array}$ & 57 episodes & $\begin{array}{l}\text { Hospital costs, mean (no ranges) } \\
\text { TCA }(n=29) £ 584 \\
\text { SSRI }(n=28) £ 213 \\
\text { TCA }: \text { SSRI costs }=\mathbf{2} \cdot \mathbf{7 4}: \mathbf{1}\end{array}$ \\
\hline $\begin{array}{l}\text { Bosch et al. } \\
\text { (2000, Netherlands) }\end{array}$ & 55 & $\begin{array}{l}\text { Retrospective case review of all admissions to ITU following DSP with single } \\
\text { antidepressant drug from } 01 / 1994 \text { to } 12 / 1998.33 \cdot 3 \% \text { of all ODs admitted to ITU. M : F } \\
1: 2 \cdot 9 \text {. Data unclear in places. Effects of co-ingestants on length of stay and procedures } \\
\text { required are unclear }\end{array}$ & 86 patients & $\begin{array}{l}\text { Length of hospital stay, days } \\
\text { TCA }(n=65) 3 \cdot 1 \\
\text { SSRIs }(n=20) 2 \cdot 3 \\
\text { TCA : SSRI (ITU days) }=\mathbf{1} \cdot \mathbf{3}: \mathbf{1}\end{array}$ \\
\hline $\begin{array}{l}\text { Ramchandani et al. } \\
(2000, \text { UK) }\end{array}$ & 64 & $\begin{array}{l}\text { Retrospective audit of } 1165 \text { episodes of DSH presenting to hospital in } 1996.19 \% \text { used } \\
\text { single antidepressant in OD. No toxicological confirmation. M }: \text { F } 1: 1 \cdot 6 \text {. Average cost of } \\
\text { TCA and SSRI adjusted for younger mean age of SSRI group }(31 \cdot 9 v \cdot 37 \cdot 4 \text { years })\end{array}$ & 220 episodes & $\begin{array}{l}\text { Hospital costs, mean } \\
\text { TCA }(n=151) £ 598 \\
\text { SSRI }(n=69) £ 298 \\
\text { Difference }(95 \% \text { CI }) £ 300(152-447) \\
\text { TCA : SSRI costs }=\mathbf{2 \cdot 0 1 : 1}\end{array}$ \\
\hline $\begin{array}{l}\text { Kapur et al. } \\
(2001, \text { UK) }\end{array}$ & 86 & $\begin{array}{l}\text { Prospective consecutive DSP presentations to three teaching hospitals and three DGH } \\
\text { between } 1 / 11 / 1998 \text { and } 31 / 3 / 1999 \text { due to TCA or SSRI OD. M }: \text { F } 1: 1 \cdot 3.12 \cdot 5 \% \text { of all DSP } \\
\text { reported in Kapur et al. }(2002 b) \text {. Past DSH in } 33 \% \text {. Costs divided into ED assessment, IP } \\
\text { days, ITU days, psychiatric assessment }\end{array}$ & 223 episodes & $\begin{array}{l}\text { Hospital costs, mean (s.D.) } \\
\text { TCA }(n=124) £ 634(911 \cdot 5) \\
\text { SSRI }(n=99) £ 173(127) \\
\text { Difference }(95 \% \text { CI }) £ 461(303-617) * \\
\text { TCA : SSRI costs }=\mathbf{3 \cdot 6 6 : 1}\end{array}$ \\
\hline $\begin{array}{l}\text { Whyte et al. } \\
\text { (2003, Australia) }\end{array}$ & 55 & $\begin{array}{l}\text { Prospective cohort of all first admissions following DSP with single agent antidepressant } \\
\text { drug from } 11 / 1994 \text { to } 04 / 2000(15 \cdot 5 \% \text { of all DSP admissions). M : F } 1: 1 \cdot 25 \text {. Dothiepin } \\
(n=82) \text { excluded from TCA analysis due to high OR for seizures } v \text {. other TCAs (adjusted } \\
\text { OR }=8 \cdot 9, p=0 \cdot 005) \text {. Effects of co-ingested pro-convulsive drugs unclear }\end{array}$ & $\begin{array}{l}538 \text { patients } \\
\text { TCA }=254 \\
\text { VLF }=51 \\
\text { SSRI }=233\end{array}$ & $\begin{array}{l}\text { Time in hospital, hours (range) } \\
\text { TCA } 23 \cdot 2(2 \cdot 8-282) \\
\text { VLF } 18 \cdot 5(0 \cdot 8-330 \cdot 2) \\
\text { SSRI } 15 \cdot 3(2-185 \cdot 5) \\
\text { ITU admission required } \\
\text { TCA }(n=172) 45 \cdot 9 \% \\
\text { VLF }(n=51) 29 \cdot 4 \% \\
\text { SSRI }(n=233) 7 \cdot 3 \% \\
\text { TCA }: \text { SSRI (hospital days) }=\mathbf{1 \cdot 5}: \mathbf{1}\end{array}$ \\
\hline
\end{tabular}

DSH, Deliberate self-harm; DSP, deliberate self-poisoning; OD, overdose; M : F, male: female ratio; TCA, tricyclic antidepressant; SSRI, selective serotonin re-uptake inhibitor; HA, heterocyclic antidepressants; VLF, venlafaxine; ED, emergency department; IP, inpatient; ITU, intensive therapy unit; OR, odds ratio; CI, confidence interval; DGH, district general hospital.

* Difference calculated using non-parametric bootstrap. 
Table 3. Summary of consecutive DSH presentation studies

\begin{tabular}{|c|c|c|}
\hline $\begin{array}{l}\text { Authors } \\
\text { (date, place) }\end{array}$ & $\begin{array}{l}\text { Quality } \\
\text { rating } \\
(\%)\end{array}$ & Study details \\
\hline $\begin{array}{l}\text { Piper \& Griner } \\
\text { (1974, USA) }\end{array}$ & 33 & $\begin{array}{l}\text { Retrospective case review of all } \\
\text { presentations of DSP with psychotropic } \\
\text { drugs between } 1968 \text { and } 1972 \text {. New RCU } \\
\text { opened } 1970 \text { and all eligible patients } \\
\text { managed on that ward from then on. } \\
\text { Historical control. M:F } 1: 1 \cdot 6\end{array}$ \\
\hline $\begin{array}{l}\text { Yeo } \\
(1993, \text { UK })\end{array}$ & 57 & $\begin{array}{l}\text { Retrospective audit of consecutive DSH } \\
\text { presentations ( } 94 \% \text { DSP) } 6 / 1990-9 / 1990 \\
\text { to DGH ED. M : F } 1: 1 \cdot 6 \text {. Past DSH in } \\
63 \% \text {. Analysis using episode not patient } \\
\text { data }\end{array}$ \\
\hline $\begin{array}{l}\text { Robicsek et al. } \\
(1993, \text { USA })\end{array}$ & 36 & $\begin{array}{l}\text { Prospective consecutive case series of all } \\
\text { injuries presenting to hospital between } \\
1 / 10 / 1989 \text { and } 30 / 9 / 1990 \text {. Data given } \\
\text { separately for DSH (59\% DSP, } 26 \% \\
\text { lacerations, } 7 \cdot 5 \% \text { firearms). M:F } 1: 0 \cdot 72\end{array}$ \\
\hline $\begin{array}{l}\text { Waller et al. } \\
\text { (1994, USA) }\end{array}$ & 29 & $\begin{array}{l}\text { Prospective presentations of violence/injury } \\
\text { on } 109 \text { random sample of days between } 3 / \\
1991 \text { and 3/1992. Data given separately for } \\
\text { DSH (59\% DSP, } 27 \% \text { lacerations). M : F } \\
1: 1.75\end{array}$ \\
\hline $\begin{array}{l}\text { Runeson \& } \\
\text { Wasserman } \\
\text { (1994, Sweden) }\end{array}$ & 57 & $\begin{array}{l}\text { Prospective consecutive series of } 100 \text { DSH } \\
\text { presentations ( } 84 \% \text { DSP) between } 1 / 9 / \\
1991 \text { and } 31 / 12 / 1991 . \text { M }: \text { F } 1: 1 \cdot 7 \text {. Past } \\
\text { DSH in } 53 \% \text {. Follow-up to } 3 / 52 \\
\text { post-discharge }\end{array}$ \\
\hline $\begin{array}{l}\text { Gunnell et al. } \\
\text { (1996 UK) }\end{array}$ & 40 & $\begin{array}{l}\text { Retrospective analysis of routine } \\
\text { information systems }\end{array}$ \\
\hline $\begin{array}{l}\text { Schiodt et al. } \\
\text { (1997, USA) }\end{array}$ & 33 & $\begin{array}{l}\text { Retrospective case series of management of } \\
\text { paracetamol toxicity between } 1 / 1 / 1992 \text { and } \\
30 / 4 / 1995 \text {. DSP cases compared with } \\
\text { accidental poisoning. M : F } 1: 2 \cdot 8\end{array}$ \\
\hline $\begin{array}{l}\text { Gunawardana \& } \\
\text { Abeywarna } \\
\text { (1997, Sri Lanka) }\end{array}$ & 38 & $\begin{array}{l}\text { Retrospective case-note series of all ITU } \\
\text { admissions following DSP } 1991-1995 . \\
\text { M : F } 2 \cdot 3: 1.85 \% \text { organophosphate } \\
\text { poisoning. No details on resource use other } \\
\text { than ITU procedures }\end{array}$ \\
\hline $\begin{array}{l}\text { Whyte et al. } \\
\text { (1997, Australia) }\end{array}$ & 40 & $\begin{array}{l}\text { Prospective descriptive evaluation of new } \\
\text { Regional Toxicology Centre. All patients } \\
\text { presenting 1987-1995, DSP patients } \\
\text { presented separately. No data on gender, } \\
\text { type of DSP or number of repeaters }\end{array}$ \\
\hline
\end{tabular}

Episode

(patient)

number

Summary of resource use

$\begin{array}{llr}119 \text { admitted } & \begin{array}{l}\text { Mean hospital costs (range) } \\ \text { Pre RCU: } \$ 1822(\$ 194-\$ 8548)\end{array} & \begin{array}{c}\text { LOS shorter on RCU but costs higher 119 } \\ \text { admitted to medical beds of } 337 \text { assessed in ED }\end{array} \\ & \text { Post RCU: } \$ 1804(\$ 301-\$ 5788)\end{array} \quad$.

$190(178)$

178 patients presented 190 times in 9/12 Average cost per patient $£ 425$ (no ranges given)

375 patients Total hospital charges for DSH/suicide (362 DSH,

13 suicides) $(n=375)$ : $\$ 4570$ per person Total charges for assaults $(n=4874)$ : $\$ 1446$ per person

22 patients

\section{Mean hospital cost (s.D.)}

DSH group \$2639 (3565)

Assault group $£ 420$ (1658)

Unknown intent \$388 (1219)

97 patients

Mean hospital costs - somatic Rx SEK $20207(n=55)$

Mean hospital costs - follow-up

SEK $51604(n=55)$

$5770(5080)$

50 patients

Median length of hospital stay

1 day (no ranges given)

Median hospital costs (range)

DSH group \$6899 (632-44976)

\section{Mean length ITU stay}

6 days (range 1-32)

$52 \%$ required mechanical ventilation

Median hospital stay, hours (range) $16 \cdot 2(0 \cdot 6-315 \cdot 9)$

$584(483)$
Accidental \$5897 (1019-81 558)

DSH patients more likely to be admitted to medical bed or ITU from ED than assault or accident patients

Resource use includes those who died during admission

Costs of managing DSH are higher than other forms of injury. Record of + ve blood alcoho higher with attempted suicide than other forms of violence

Six left prior to assessment. 76 referred for aftercare of whom $62 \%$ had full compliance and $18 \%$ partial compliance

$10 \%$ of admissions received additional psychiatric in-patient care

Median hospital stay, days (range)

DSH group $(n=50) 3(1-23)$

Accidental $(n=21) 4(1-51)$

Opportunity cost estimated to be 114 other critically ill patients denied treatment due to resource use by DSP patients requiring ITU
96/584 (16.4\%) require ITU admission. 520/584 $(89 \%)$ received psychiatric assessment. Calculations on episodes not patients 


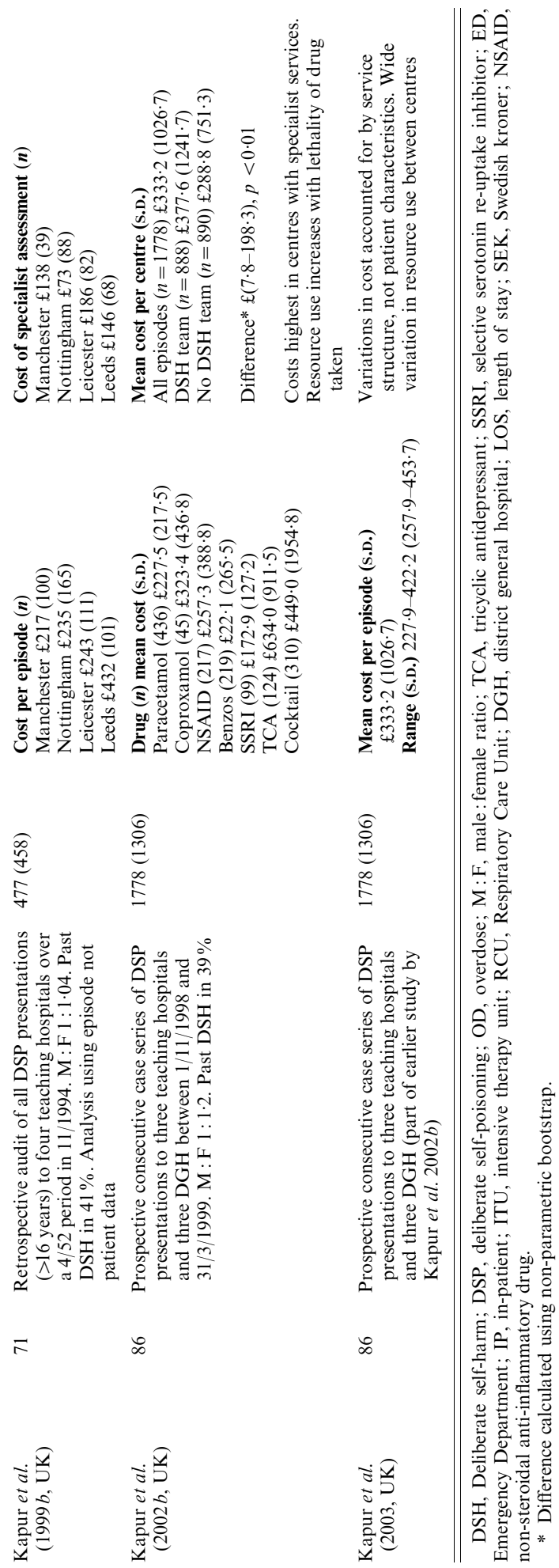

assumption has to be that these overdoses were medically less serious, possibly with lower doses of TCAs or alcohol ingested. What is clear from both studies is the relative increase in resources required to manage SSRI overdoses when combined with alcohol than when taken alone.

\section{Studies investigating consecutive DSH presentations}

Five studies investigated consecutive DSH presentations at one or more sites (Yeo, 1993; Runeson \& Wasserman, 1994; Gunnell et al. 1996; Kapur et al. 1999 b, 2002 b). In the study by Yeo (1993), resource utilization was aggregated from emergency department assessment, medical/surgical in-patient days, ITU days and psychiatric assessment. This format was used as a template for the later UK studies (Kapur et al. $1999 b, 2002 b$ ).

\section{Characteristics of patient samples}

All five studies had a similar male to female ratio (mean $1: 1 \cdot 3$, range $1 \cdot 04-1 \cdot 70$ ), and the mean age was 33.3 years (range 30.9-38.0 years). The prevalence of prior DSH based on aggregating data from four of these studies (Yeo, 1993; Runeson \& Wasserman, 1994; Kapur et al. 1999b, 2002b) was 41.0\% (1026/ 2500 ; range in individual studies $38 \cdot 6-53 \cdot 4 \%$ ). Rates within one multi-centre study (Kapur et al. $2002 b$ ) varied from $29 \%$ to $50 \%$ between sites. Self-discharge rates were available in three studies, and were $6.2 \%$ in the Swedish study (Runeson \& Wasserman, 1994), 6.8\% in an earlier UK study (Yeo, 1993), and $17 \cdot 6 \%$ in the more recent UK study (Kapur et al. 2002b).

\section{Resource utilization}

Emergency department assessment and hospital admission. All patients received some form of emergency department assessment, following which hospital admission occurred on average in $45.5 \%$ of cases $(1154 / 2536$; range 83.0 $37.9 \%$ ) across the four clinical studies. The proportion of patients admitted to hospital in the UK decreased from $83 \%$ in 1990 (Yeo, 1993), to 66\% in 1992 (Gunnell et al. 1996), $57 \%$ in 1996 (Kapur et al. 1999 b) and 37.9\% in 1999 (Kapur et al. 2002 b). For those patients who were admitted, the mean length of hospital stay was 1.8 days (2074 days admission for 1154 persons). This compares with a median hospital 
length of stay of 1 day found in two studies (Yeo 1993; Gunnell et al. 1996), illustrating the significant right skew in length of hospital stay arising from long stays by a small number of people.

Management on the ITU. Management on the ITU occurred in less than $2 \%$ of patients (Yeo, 1993; Kapur et al. 1999 b), making up $5.7 \%$ of in-patient days of those admitted to hospital, although this varied from $2.6 \%$ in the UK studies (Yeo, 1993; Kapur et al. 1999b) to $23.3 \%$ in the Swedish study (Runeson \& Wasserman, 1994). From the data available it is not possible to say whether this was due to differences in management protocols between the two countries, or whether the medical severity of the acts of DSH in the two populations differed (Michel et al. 2000). Days on ITU in the UK studies account for between $8 \%$ (Yeo, 1993; Kapur et al. 1999b) and 21\% (Kapur et al. 2002b) of the total cost.

Psychosocial assessment. The proportion of patients referred for a specialist psychosocial assessment showed significant variation between studies, as well as within studies at different sites. Overall, 47.4\% (1203/2536; range in individual studies $42.9-90 \%$ ) were referred for a specialist psychosocial assessment. In multicentre studies, rates varied between 39\% and $74 \%$ between sites. There were also significant differences in who provided these assessments and the service structure in which they were based. In the earlier studies (Yeo, 1993; Runeson \& Wasserman, 1994) psychosocial assessments were carried out by the duty psychiatrist; more recent studies have identified a range of mental health professionals carrying out assessments as part of a specialist service in some centres while the previous provision continues in others. In none of the studies did authors attempt to estimate the cost of delivery of a specialist DSH service, and they either incorporated the costs into the ward unit costs (Runeson \& Wasserman, 1994) or approximated them as being equal to a psychiatric outpatient appointment (Yeo, 1993; Kapur et al. $1999 a)$.

Follow-up arrangements. Admission to a psychiatric in-patient facility as aftercare occurred in $9.7 \%$ of cases $(587 / 6057$; range in individual studies $5 \cdot 8-10 \cdot 0 \%$ ) in the three studies giving details (Yeo, 1993; Runeson \& Wasserman, 1994; Gunnell et al. 1996), with a further $29.6 \%$ (85/287; range $22.6-42 \%)$ referred for outpatient psychiatric follow-up (Yeo, 1993; Runeson \& Wasserman, 1994). In two recent UK studies (Kapur et al. 1999b, 2002b) an average of $35 \%$ of patients were referred for 'specialist' follow-up (791/2255; range 32$45 \%$ ), which included both in- and out-patient psychiatric care.

\section{Methods of DSH}

The method of DSH, and its associated medical complications, was a key factor in resource utilization. Violent methods, such as firearm injuries, were responsible for a significant right skew in costs of management because of increased length of in-patient stay, use of ITU and high in-patient mortality rates $(67 \%)$ in the studies that included them (Robicsek et al. 1993; Waller et al. 1994). No specific details were given on resources required in other forms of self-injury, particularly carbon monoxide poisoning or hanging. To a lesser extent, the choice of substance used in DSP and the coingestion of alcohol or other respiratory depressant drugs also result in significant differences in resource use. In Sri Lanka, where DSP with organophosphates is common, $85 \%$ of ITU admissions were accounted for by organophosphate poisoning (Gunawardana \& Abeywarna, 1997). In this review, in the high-income countries, TCAs and overdose 'cocktails' of psychotropic drugs resulted in highest use of costly medical resources such as in-patient days and ITU (Stoner et al. 1997; Palmer et al. 1998; Kapur et al. $1999 a, 2001,2002$ b; Ramchandani et al. 2000).

\section{Resource utilization factors}

Resource utilization was affected by the threshold for admission from the emergency department to a medical bed. The two studies that evaluated this at a service level (Piper \& Griner, 1974; Whyte et al. 1997) suggested that an integrated admissions policy reduced medical complications and therefore resource use. In the more recent and methodologically robust Australian study (Whyte et al. 1997), all patients were admitted to a centralized Regional Unit 
with high rates of psychosocial assessment $(89 \%)$. In this study a centralized multidisciplinary assessment service resulted in a reduction in length of hospital stay, especially in complicated co-morbid cases, and, despite the slightly higher unit costs, resulted in an overall cost saving.

Results of the two multi-centre urban studies conducted in the UK (Kapur, 1999b, 2003) suggest that several factors independent of patient characteristics affected whether or not patients were subsequently referred for specialist assessment. These included admission policies in different sites, time of day at which the patient presented and, in those hospitals without a specialist assessment team, the proximity of the local psychiatric service. In these studies, those who received a specialist assessment were less likely to repeat DSH in the short term compared with those who did not $(9 \cdot 8 \% v$. $17.9 \%, p<0.005)$.

Patients receiving a specialist psychosocial assessment were also more likely to be referred for specialist follow-up. However, other than the Swedish study, which recorded compliance rates of $62 \%$ in the follow-up period, and the small percentage $(9.7 \%)$ admitted to in-patient psychiatric care (Runeson \& Wasserman, 1994), there was no further evidence on whether patients referred for follow-up attended.

\section{Costs}

In three studies the difference in unit costs in different sites were investigated (Runeson \& Wasserman, 1994; Kapur et al. 1999b, 2002b). In each study university hospitals had greater unit costs than district general hospitals. More specialist resources and teams were likely to have been available in the university hospitals, which would also have had an impact on the pathways taken by patients through the different systems.

\section{Studies examining resource use following DSH compared with other forms of injury and poisoning}

Three studies (Robicsek et al. 1993; Waller et al. 1994; Whyte et al. 1997) investigated the resource utilization of DSH patients compared with other groups.

The two studies based in the USA (Robicsek et al. 1993; Waller et al. 1994) examined differences in service utilization between patients presenting following DSH and those who were victims of assault and/or accidental injury. In both studies $59 \%$ of the DSH patient sample had self-poisoned, $26 \%$ presented with lacerations and, in the larger of the two studies (Robicsek et al. 1993), based on 375 DSH patients (13 of whom died), 7.5\% (28/375) used firearms. This represents a major difference from the DSH populations in Europe. Both reports included some details of the concurrent use of alcohol: Waller et al. (1994) reported positive breath alcohol tests on $8 / 15$ patients for whom there were data; and Robicsek reported that $52 \%(62 / 117)$ of the breath alcohol tests reached the legal limit for intoxication. Neither gave any detail as to what impact this might have had on the resources required to manage the episodes, nor details of any psychosocial assessment or disposal data. Both studies used billing data to estimate the costs of treatment, and although the actual costs involved differed considerably between the studies (see Table 2), in both cases the average cost of managing a DSH episode was at least twice that of an assault episode.

\section{DISCUSSION}

From the studies identified in this review there appear to be three main interdependent factors that affect resource use from the supply side: threshold for admission to a medical bed; availability of a specialized liaison or on-site psychiatric service, and provision of care by a university hospital. From the demand side, the medical seriousness of DSH has a significant impact on length of hospital stay. To a lesser extent, patient characteristics recognized as risk factors for further suicidal behaviour also appear to have some impact on the management plan.

This review has not included the wider costs involved in the longer-term management following DSH (Byford et al. 2003), or specifically addressed the question of cost-effectiveness. There is as yet no conclusive evidence of the effectiveness of specific interventions targeted at the prevention of DSH (Hawton et al. 1998; Tyrer et al. 2003), no evidence of the impact of different methods of service delivery on clinical outcomes, and no consensus as to which costs 
can be attributed directly to the management of $\mathrm{DSH}$, and how much is due to underlying problems, which would still be accrued if DSH had not occurred. Consequently, examining the factors affecting resource use in $\mathrm{DSH}$, as presented in this review, helps to clarify some of these important considerations. This approach to the development and evaluation of complex interventions is proposed by the Medical Research Council, to clearly define the parameters to be measured prior to undertaking further randomized controlled trials (Campbell et al. 2000).

It was not appropriate to carry out a formal meta-analysis on these results (Egger et al. 1998), particularly as management occurred in different populations across varied health systems. The mixed quality of the studies and lack of consistency in how resource use is recorded and described also limits the confidence that can be attached to the conclusions drawn. In addition, some factors described were investigated in only one study. This highlights the need for good quality multi-centre studies to incorporate economic aspects and the impact of service structure into trial protocols. The checklist used to rate studies in this review, based on key principles for simple economic evaluations that are well documented in the literature (Drummond et al. 1997; Cooper, 2000), provides a basis on which to conduct such future evaluations.

Variation in service delivery appears to be a significant factor affecting resource utilization (Hultén et al. 2000; Kapur et al. 2003). A recent study (Bennewith et al. 2004) showed that the variability remains as broad as ever. The data from this review suggest that alterations in one part of the system (e.g. policy on medical admission, or the presence of a specialist DSH service) are interdependent with other aspects of resource utilization. While there is some evidence that those who receive a psychosocial assessment have reduced rates of repetition in the short term (Crawford \& Wessely, 1998; Kapur et al. 2003), it is not known what effect different pathways through services might have on outcome, or whether this may account for the variability seen across different health systems.

A consistent finding across the studies reviewed was the high cost of medical management on ITU, which, although occurring in relatively few patients, accounted for a disproportionately large cost burden. Second to this in cost, but more prevalent, was the resources required for in-patient management on a medical or surgical ward. DSH is one of the top five reasons for admission to hospital emergency departments in men and women (NHS Centre for Reviews and Dissemination, 1998). Although the majority of patients were admitted for an average of 1 day, the large and increasing number of patients presenting to hospital following an episode of DSH means this has significant resource implications.

One of the limitations of all the studies reviewed is that the costs of providing assessments following DSH were based on reference unit costs for an out-patient appointment. There are no reference costs available for specialist DSH services. Given current resource limitations in terms of trained staff and financial provision within most mental health-care systems, an estimation of the cost and opportunity cost of providing these services is an essential component in any consideration of the cost-effectiveness of interventions aimed at the secondary prevention of $\mathrm{DSH}$, and attempts to define reference costs for these services are sorely needed.

Emergency department resource use was costed using unit costs and in some studies additional treatment procedures were recorded separately (Yeo, 1993; Runeson \& Wasserman, 1994). However, there is little research evidence to support the clinical impression that DSH patients are often burdensome in terms of the staff time required for their management. The decrease in percentage of patients admitted to medical beds over the past two decades as a result of changing policies is highlighted by this review. During the same time period DSH rates have risen significantly (Hawton et al. 1997; O'Loughlin \& Sherwood, 2005). This association may be an ecological fallacy, but as with other epidemiological trends relating to suicidal behaviour it warrants further investigation.

In terms of DSP with psychotropic drugs, which remains the most common method of DSH in Europe (Michel et al. 2000), one of the most consistent findings of this review is that resource use is more than $2 \cdot 5$ times greater in the management of poisoning with TCAs than 
with SSRIs. In the prevention of suicide, the lethality of available methods for suicidal behaviour is a key factor in the likelihood of suicide following DSH (Gunnell \& Lewis, 2005). While there is no substantial evidence of a significant causal link between SSRIs and the provocation of suicidal behaviour (Gunnell et al. 2005; Martinez et al. 2005), recent concerns about the possibility of such an association may alter prescribing behaviour (Martin et al. 2006) and may result in a return to prescribing of TCAs, with a consequent potential increase in the number of fatalities as well as resources required in the short-term management of DSH.

Combinations of psychotropic drugs and coingestion of alcohol also have a significant impact on resource utilization. With the increased availability and relative reduction in price of alcohol in the UK this is likely to become an increasingly important factor (Academy of Medical Sciences, 2004). The wide use of firearms for DSH and suicide in the USA (Kellermann et al. 1992) and pesticide use in Sri Lanka (Gunawardana \& Abeywarna, 1997) highlights the importance of national epidemiological patterns of DSH in estimating resource use in the hospital management of DSH.

\section{CONCLUSIONS}

There is some evidence that not only the method and medical seriousness of DSH but also variations in service provision affect the resources used in its short-term hospital management. However, there is little evidence for the impact that different models of care may have on clinical outcome or longer-term resource utilization, and further research is needed to address this question using prospective studies well designed for this purpose. Given the current variation in service provision to patients following an episode of DSH, understanding the impact of these differences may have significant implications for clinical care, as well as the evaluation of costeffectiveness of any specific interventions in this patient group. The findings of this review also highlight the significant differences in medical care required following overdose with TCAs compared with SSRIs, which should be considered in making prescribing decisions, together with the likelihood of co-ingestion of alcohol. Further research is also needed to evaluate the impact of DSP with psychotropic drugs combined with alcohol, as recent legislation increasing the availability of alcohol in the UK is likely to make this an increasing problem.

\section{ACKNOWLEDGEMENTS}

Julia Sinclair is funded by the Medical Research Council, Alastair Gray by HEFCE, and Keith Hawton by Oxfordshire and Buckinghamshire Mental Health Partnership NHS Trust.

\section{DECLARATION OF INTEREST}

None.

\section{REFERENCES}

Academy of Medical Sciences (2004). Calling Time: the Nation's Drinking as a Major Health Issue. Academy of Medical Sciences: London.

Bennewith, O., Gunnell, D., Peters, T., Hawton, K. \& House, A. (2004). Variations in the hospital management of self harm in adults in England: observational study. British Medical Journal 328, 1108-1109.

Bosch, T. M., Van der Werf, T. S., Uges, D. R. A., Ligtenberg, J. J. M., Fijen, J. W., Tulleken, J. E. \& Zijlstra, J. G. (2000). Antidepressants self-poisoning and ICU admissions in a University Hospital in the Netherlands. Pharmacy World and Science 22, 92-95.

Buckley, N. A., Dawson, A. H., Whyte, I. M. \& Henry, D. A. (1994). Greater toxicity in overdose of dothiepin than of other tricyclic antidepressants. Lancet 343, 159-162.

Byford, S., Barber, J. A. \& Harrington, R. (2001). Factors that influence the cost of deliberate self-poisoning in children and adolescents. Journal of Mental Health Policy and Economics 4, 113-121.

Byford, S., Knapp, M., Greenshields, J., Ukoumunne, O., Jones, V., Thompson, S., Davidson, K., Schmidt, U., Tyrer, P., Catalan, J., Airlie, J., Baxter, S., Byrne, G., Cameron, S., Caplan, R., Cooper, S., Ferguson, B., Fowler, L. \& Freeman, C. (2003). Costeffectiveness of brief cognitive behaviour therapy versus treatment as usual in recurrent deliberate self-harm: a decision-making approach. Psychological Medicine 33, 977-986.

Campbell, M., Fitzpatrick, R., Haines, A., Kinmonth, A. L., Sandercock, P., Spiegelhalter, D. \& Tyrer, P. (2000). Framework for design and evaluation of complex interventions to improve health. British Medical Journal 321, 694-696.

Cooper, N. J. (2000). Economic burden of rheumatoid arthritis: a systematic review. Rheumatology (Oxford) 39, 28-33.

Crawford, M. J. \& Wessely, S. (1998). Does initial management affect the rate of repetition of deliberate self-harm? Cohort study. British Medical Journal 317, 985.

D'Mello, D. A., Finkbeiner, D. S. \& Kocher, K. N. (1995). The cost of antidepressant overdose. General Hospital Psychiatry 17, 454-455.

Drummond, M. F., O'Brien, B. J., Stoddart, G. L. \& Torrance, G. W. (1997). Methods for the Economic Evaluation of Health Care Programmes (2nd edn). Oxford Medical Publications: Oxford.

Egger, M., Schneider, M. \& Davey, S. G. (1998). Spurious precision? Meta-analysis of observational studies. British Medical Journal 316, 140-144.

Gunawardana, R. H. \& Abeywarna, C. (1997). Intensive care utilisation following attempted suicide through self-poisoning. Ceylon Medical Journal 42, 18-20. 
Gunnell, D. \& Lewis, G. (2005). Studying suicide from the life course perspective: implications for prevention. British Journal of Psychiatry 187, 206-208.

Gunnell, D., Saperia, J. \& Ashby, D. (2005). Selective serotonin reuptake inhibitors (SSRIs) and suicide in adults: meta-analysis of drug company data from placebo controlled, randomised controlled trials submitted to the MHRA's safety review. British Medical Journal 330, 385.

Gunnell, D. J., Brooks, J. \& Peters, T. J. (1996). Epidemiology and patterns of hospital use after parasuicide in the south west of England. Journal of Epidemiology and Community Health 50, 24-29.

Hawton, K., Arensman, E., Townsend, E., Bremner, S., Feldman, E., Goldney, R., Gunnell, D., Hazell, P., Van Heeringen, C., House, A., Owens, D., Sakinofsky, I. \& Traskman-Bendz, L. (1998). Deliberate self-harm: systematic review of efficacy of psychosocial and pharmacological treatments in preventing repetition. British Medical Journal 317, 441-447.

Hawton, K., Fagg, J., Simkin, S., Bale, E. \& Bond, A. (1997). Trends in deliberate self-harm in Oxford, 1985-1995. Implications for clinical services and the prevention of suicide. British Journal of Psychiatry 171, 556-560.

Hultén, A., Wasserman, D., Hawton, K., Jiang, G.-X., SalanderRenberg, E., Schmidtke, A., Bille-Brahe, U., Bjerke, T., Kerkhof, A., Michel, K. \& Querejeta, I. (2000). Recommended care for young people (15-19 years) after suicide attempts in certain European countries. European Child and Adolescent Psychiatry 9, 100-108.

Jick, H., Kaye, J. A. \& Jick, S. S. (2004). Antidepressants and the risk of suicidal behaviors. Journal of the American Medical Association 292, 338-343.

Kapur, N., House, A., Creed, F., Feldman, E., Friedman, T. \& Guthrie, E. (1999a). Costs of antidepressant overdose: a preliminary study. British Journal of General Practice 49, 733-734.

Kapur, N., House, A., Creed, F., Feldman, E., Friedman, T. \& Guthrie, E. $(1999 b)$. General hospital services for deliberate self-poisoning: an expensive road to nowhere? Postgraduate Medical Journal 75, 599-602.

Kapur, N., House, A., Dodgson, K., May, C. \& Creed, F. (2001). Hospital management and costs of antidepressant overdose: multicentre comparison of tricyclic antidepressants and selective serotonin reuptake inhibitors. Journal of Medical Economics 4, 193-197.

Kapur, N., House, A., Dodgson, K., May, C. \& Creed, F. (2002a). Effect of general hospital management on repeat episodes of deliberate self poisoning: cohort study. British Medical Journal 325, 866-867.

Kapur, N., House, A., Dodgson, K., May, C., Marshall, S., Tomenson, B. \& Creed, F. (2002b). Management and costs of deliberate selfpoisoning in the general hospital: a multi-centre study. Journal of Mental Health UK 11, 223-230.

Kapur, N., House, A., May, C. \& Creed, F. (2003). Service provision and outcome for deliberate self-poisoning in adults: results from a six centre descriptive study. Social Psychiatry and Psychiatric Epidemiology 38, 390-395.

Kellermann, A. L., Rivara, F. P., Somes, G., Reay, D. T., Francisco, J., Banton, J. G., Prodzinski, J., Fligner, C. \& Hackman, B. B. (1992). Suicide in the home in relation to gun ownership. New England Journal of Medicine 327, 467-472.

Martin, R. M., May, M. \& Gunnell, D. (2006). Did intense adverse media publicity impact on prescribing of paroxetine and the notification of suspected adverse drug reactions? Analysis of routine databases, 2001-2004. British Journal of Clinical Pharmacology 61, 224-228.

Martinez, C., Rietbrock, S., Wise, L., Ashby, D., Chick, J., Moseley, J., Evans, S. \& Gunnell, D. (2005). Antidepressant treatment and the risk of fatal and non-fatal self harm in first episode depression: nested case-control study. British Medical Journal 330, 389.

Michel, K., Ballinari, P., Bille-Brahe, U., Bjerke, T., Crepet, P., De Leo, D., Haring, C., Hawton, K., Kerkhof, A., Lönnqvist, J.,
Querejeta, I., Salander-Renberg, E., Schmidtke, A., Temesvary, B. \& Wasserman, D. (2000). Methods used for parasuicide: results of the WHO/EURO Multicentre Study on Parasuicide. Social Psychiatry and Psychiatric Epidemiology 35, 156-163.

NHS Centre for Reviews and Dissemination (1998). Effective Health Care Bulletin: Deliberate Self-harm. Effective Health Care 4, 1-12.

NICE (2004). Self-harm: the short-term physical and psychological management and secondary prevention of self-harm in primary and secondary care. Clinical guideline 16. National Institute for Clinical Excellence, London.

O'Loughlin, S. \& Sherwood, J. (2005). A 20-year review of trends in deliberate self-harm in a British town, 1981-2000. Social Psychiatry and Psychiatric Epidemiology 40, 446-453.

Palmer, C. S., Kleinman, L., Taylor, L. A. \& Revicki, D. A. (1998). Pharmacoeconomics of antidepressant drug overdose. CNS Drugs 10, 223-231

Piper, K. W. \& Griner, P. F. (1974). Suicide attempts with drug overdose. Outcomes of intensive vs conventional floor care. Archives of Internal Medicine 134, 703-706.

Platt, S., Bille-Brahe, U., Kerkhof, A., Schmidtke, A., Bjerke, T., Crepet, P., De Leo, D., Haring, C., Lönnqvist, J., Michel, K., Phillippe, A., Pommereau, X., Querejeta, I., Salander-Renberg, E., Temesvary, B., Wasserman, D. \& Sampaio-Faria, J. G. (1992). Parasuicide in Europe: the WHO/EURO Multicentre Study on Parasuicide. 1. Introduction and preliminary analysis for 1989. Acta Psychiatrica Scandinavica 85, 97-104.

Ramchandani, P., Murray, B., Hawton, K. \& House, A. (2000). Deliberate self poisoning with antidepressant drugs: a comparison of the relative hospital costs of cases of overdose of tricyclics with those of selective-serotonin re-uptake inhibitors. Journal of Affective Disorders 60, 97-100.

Revicki, D. A., Palmer, C. S., Phillips, S. D., Reblando, J. A. Heiligenstein, J. H., Brent, J. \& Kulig, K. (1997). Acute medical costs of fluoxetine versus tricyclic antidepressants. A prospective multicentre study of antidepressant drug overdoses. Pharmacoeconomics 11, 48-55.

Robicsek, F., Ribbeck, B., Walker, L. G., Thomason, M. H., Hollenbeck, J. I. \& Baker, J. W. (1993). The cost of violence. The economy of health care delivery for non-accidental trauma in an urban southeastern community. North Carolina Medical Journal 54, 578-582.

Royal College of Psychiatrists (1994). The General Hospital Management of Adult Deliberate Self-Harm. Council Report CR32. Royal College of Psychiatrists: London.

Royal College of Psychiatrists (2004). Assessment Following SelfHarm in Adults. Council Report CR122. Royal College of Psychiatrists: London.

Runeson, B. \& Wasserman, D. (1994). Management of suicide attempters: what are the routines and the costs? Acta Psychiatrica Scandinavica 90, 222-228.

Schiodt, F. V., Rochling, F. A., Casey, D. L. \& Lee, W. M. (1997). Acetaminophen toxicity in an urban county hospital. New England Journal of Medicine 337, 1112-1117.

Schmidtke, A., Bille Brahe, U., De Leo, D., Kerkhof, A., Bjerke, T., Crepet, P., Haring, C., Hawton, K., Lönnqvist, J., Michel, K., Pommereau, X., Querejeta, I., Phillipe, I., Salander Renberg, E., Temesvary, B., Wasserman, D., Fricke, S., Weinacker, B. \& Sampaio Faria, J. G. (1996). Attempted suicide in Europe: rates, trends and sociodemographic characteristics of suicide attempters during the period 1989-1992. Results of the WHO/EURO Multicentre Study on Parasuicide. Acta Psychiatrica Scandinavica 93, 327-338

Sinclair, J. M. A., Birtwistle, J. \& Baldwin, D. S. (1998). The tolerability of venlafaxine. Reviews in Contemporary Pharmacotherapy 9, 333-342.

Stoner, S. C., Marken, P. A., Watson, W. A., Switzer, J. L., Barber, M. F., Meyer, V. L., Sommi, R. W. J. \& Steele, M. T. (1997). Antidepressant overdoses and resultant emergency department services: the impact of SSRIs. Psychopharmacology Bulletin 33, $667-670$. 
Tyrer, P., Thompson, S., Schmidt, U., Jones, V., Knapp, M., Davidson, K., Catalan, J., Airlie, J., Baxter, S., Byford, S., Byrne, G., Cameron, S., Caplan, R., Cooper, S., Ferguson, B., Fowler, L., Freeman, C., Frost, S., Godley, J. \& Greenshields, J. (2003). Randomized controlled trial of brief cognitive behaviour therapy versus treatment as usual in recurrent deliberate-harm: the POPMACT study. Psychological Medicine 33, 969-976.

Waller, J. A., Skelly, J. M. \& Davis, J. H. (1994). Characteristics, costs, and effects of violence in Vermont. Journal of Trauma 37, 921-927.
Whyte, I. M., Dawson, A. H. \& Buckley, N. A. (2003) Relative toxicity of venlafaxine and selective serotonin reuptake inhibitors in overdose compared to tricyclic antidepressants. QJM: Monthly Journal of the Association of Physicians 96, 369-374.

Whyte, I. M., Dawson, A. H., Buckley, N. A., Carter, G. L. \& Levey, C. M. (1997). Health care. A model for the management of self-poisoning. Medical Journal of Australia 167, 142-146.

Yeo, H. M. (1993). The cost of treatment of deliberate self-harm. Archives of Emergency Medicine 10, 8-14. 